\title{
THE OUTCOME AND INDICATIONS OF THE COX MAZE III PROCEDURE FOR CHRONIC ATRIAL FIBRILLATION WITH MITRAL VALVE DISEASE
}

Fumitaka Isobe, MD

Yasunaru Kawashima, MD

\begin{abstract}
Objective: The efficacy of the Cox maze III procedure for chronic atrial fibrillation associated with mitral valve disease is unclear, and so was evaluated in this study. Methods: In 30 patients, we applied the maze III procedure (cut and suture), except for one modification in the case of a left posterior sinus node artery. After dividing the patients into sinus rhythm and atrial fibrillation groups more than 6 months after the operation, we compared various parameters. Results: Sinus rhythm was restored in 27 patients $(90 \%)$. One patient had atrioventricular reentrant tachycardia and needed a pacemaker for sick sinus syndrome (3.3\%). The f-wave voltage in lead $V_{1}$, the preoperative cardiothoracic ratio, the preoperative left atrial systolic dimension, and the duration of atrial fibrillation were $0.23 \pm 0.10$ $\mathrm{mV}, 60.4 \% \pm 5.2 \%, 57.4 \pm 8.2 \mathrm{~mm}$, respectively, and $5.1 \pm 4.6$ years in the group with sinus rhythm, and were $0.06 \pm 0.05 \mathrm{mV}, 77.7 \% \pm 10.3 \%, 95.3 \pm$ $\mathbf{2 4 . 0} \mathrm{mm}$, respectively, and $11.8 \pm 5.5$ years in the group with atrial fibrillation. These parameters were all significantly different between the groups. Regarding atrial function, a transmitral flow A wave was detected in $66.7 \%$ and a transtricuspid flow $A$ wave in $100 \%$. Only the duration of atrial fibrillation had a significant influence on the restoration of left atrial function. Conclusion: The maze III procedure was effective for atrial fibrillation associated with mitral valve disease. This procedure should be applied to patients with a cardiothoracic ratio less than $70 \%$ and a left atrial systolic dimension less than 80 mm. (J Thorac Cardiovasc Surg 1998; 116:220-7)
\end{abstract}

$\mathrm{R}^{\mathrm{s}}$ ecently, it has generally been accepted that the Cox maze procedure ${ }^{1-3}$ shows a good efficacy for lone atrial fibrillation (AF), but its efficacy has not been reported for chronic AF combined with organic heart disease, especially valvular heart disease. The good efficacy of the modified maze procedure for AF associated with mitral valve disease has already been reported. ${ }^{4-7}$ However, the procedure used in these studies was not Cox's original procedure but a modified one. In Japan, most surgeons use the modified maze procedure in which numerous cryolesions are used as a substitute for the

From the Department of Cardiovascular Surgery, National Cardiovascular Center, Osaka, Japan.

Received for publication June 27, 1997; revisions requested Oct. 20, 1997; revisions received March 4, 1998; accepted for publication March 5, 1998.

Address for reprints: Fumitaka Isobe, MD, Department of Cardiovascular Surgery, Osaka National Hospital, 2-1-14 Hoenzaka, Chuo-ku, Osaka, 540-0006, Japan.

Copyright (C) 1998 by Mosby, Inc.

0022-5223/98 \$5.00+ $0 \quad \mathbf{1 2 / 1 / 9 0 1 8 9}$ incision of the atrial wall because it is simple and also may decrease the blood loss. When substituted for the actual incision, however, cryolesion might produce a wide band of frozen atrium that will become noncontractile myocardium, which would oppose the purpose of the maze procedure. Therefore we applied the Cox maze III procedure, meaning a "cut and suture" technique, to treat chronic AF along with mitral valve surgery. This study aimed to evaluate the efficacy of the Cox procedure (cutting and suturing of the atrial wall and limited cryosurgery only on the anulus to make a maze) for terminating chronic AF in patients with mitral valve disease and to establish reasonable indications for this procedure.

\section{Patients and methods}

Patient population. From March 1993 to September 1995, 34 consecutive patients with AF as a result of mitral valve disease underwent the Cox maze III procedure with mitral valve surgery. Before the operation, we explained the detail of the surgical procedure and its possible risks 
A

\section{original maze III}
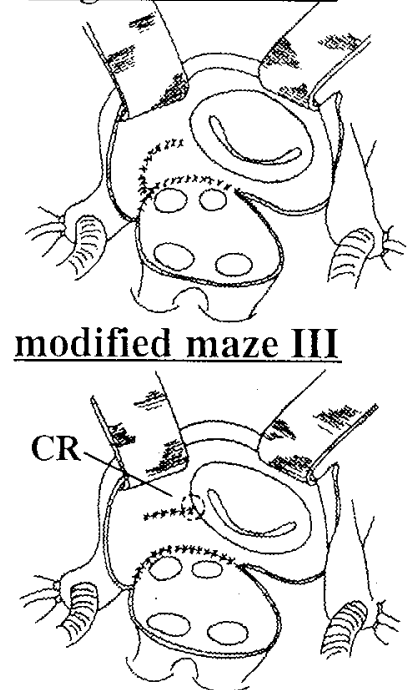

CR: cryolesion

B
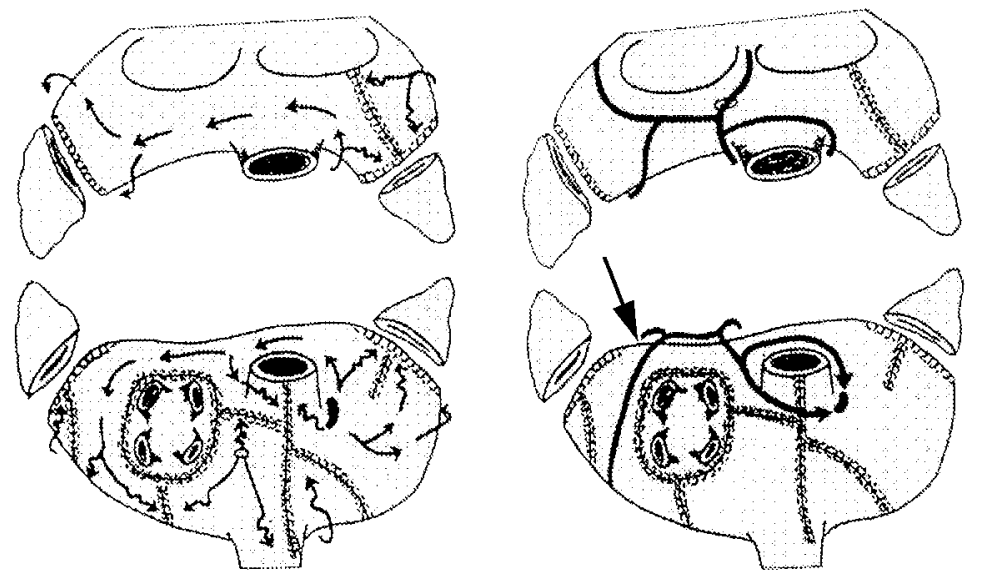

Fig. 1. Modification of the original maze III procedure. A, The modified procedure. B, The incision lines and impulse propagation after the modified procedure in the relation to the location of the sinus node arteries. Arrow shows preservation of the left posterior sinus node artery with the modified procedure.

to all patients and obtained written informed consent. In three patients, we could not perform the complete operation because of severe calcification and adhesions in the area between the left atrial appendage and the mitral anulus. We had to use cryosurgery instead of a real incision for them. In addition, one 57-year-old woman died in the early postoperative period of a rupture of the left ventricle after mitral valve replacement with a mechanical valve. These four patients were excluded from this study, and the other 30 patients were investigated. The 16 men and 14 women ranged in age from 32 to 72 years (mean $57.4 \pm 11.0$ years). The cardiac rhythm was sustained AF in 29 patients and paroxysmal AF in one patient. The mitral valve disease was rheumatic in 21 patients and degenerative in eight patients; one patient had prosthetic valve failure.

Surgical procedures. The operative procedure was mitral valve surgery alone in 12 patients. As the concomitant procedure, aortic valve surgery was done in six patients, combined aortic and tricuspid valve surgery in one patient, tricuspid valve surgery in nine patients, and coronary bypass surgery in two patients. Two patients underwent reoperation. Mitral valve surgery involved valve repair in eight patients and valve replacement in 22 patients (all with mechanical valves). Preoperative thromboembolic episodes occurred in six patients: five to the brain and one in the coronary artery.

The maze procedure we used was the same as the Cox maze III, except that, if the sinus node artery was a left posterior type arising from the left circumflex artery and running between the left atrial appendage and left superior pulmonary vein, the incision between the isolation incision for the pulmonary veins and the stump of the left atrial appendage was abandoned so as not to injure the sinus node artery and was moved to the area between the stump of the left atrial appendage and the posterior mitral anulus with a small cryolesion at the anulus like another mitral incision (Fig. 1). ${ }^{8}$ We routinely used coronary angiography to define the type of sinus node artery before the operation. If it was a left posterior type or if coronary angiography was not done because of an emergency operation, we used this modification. All patients in this series were operated on by the same surgeon.

Data acquisition. On the basis of the postoperative rhythm the subjects were divided into a sinus rhythm (SR) group and an AF group. Then the two groups were compared regarding the following points: preoperative cardiothoracic ratio (CTR) and left atrial systolic dimension on echocardiography, A wave of transmitral flow and transtricuspid flow on Doppler echocardiography, the maximum voltage of the preoperative $f$ wave in lead $V_{1}$ on the electrocardiogram, and the duration of AF.

Statistical analysis. Continuous variables were compared with the Mann-Whitney $U$ test. The statistical analysis was performed with a software package (StatView J-4.5; Abacus Concepts, Inc., Berkeley, Calif.).

\section{Results}

Operative procedure, mortality and morbidity rates. The original Cox procedure was performed in 15 patients, and our modification was done in 15 . The cardiac arrest time ranged from 95 to 229 

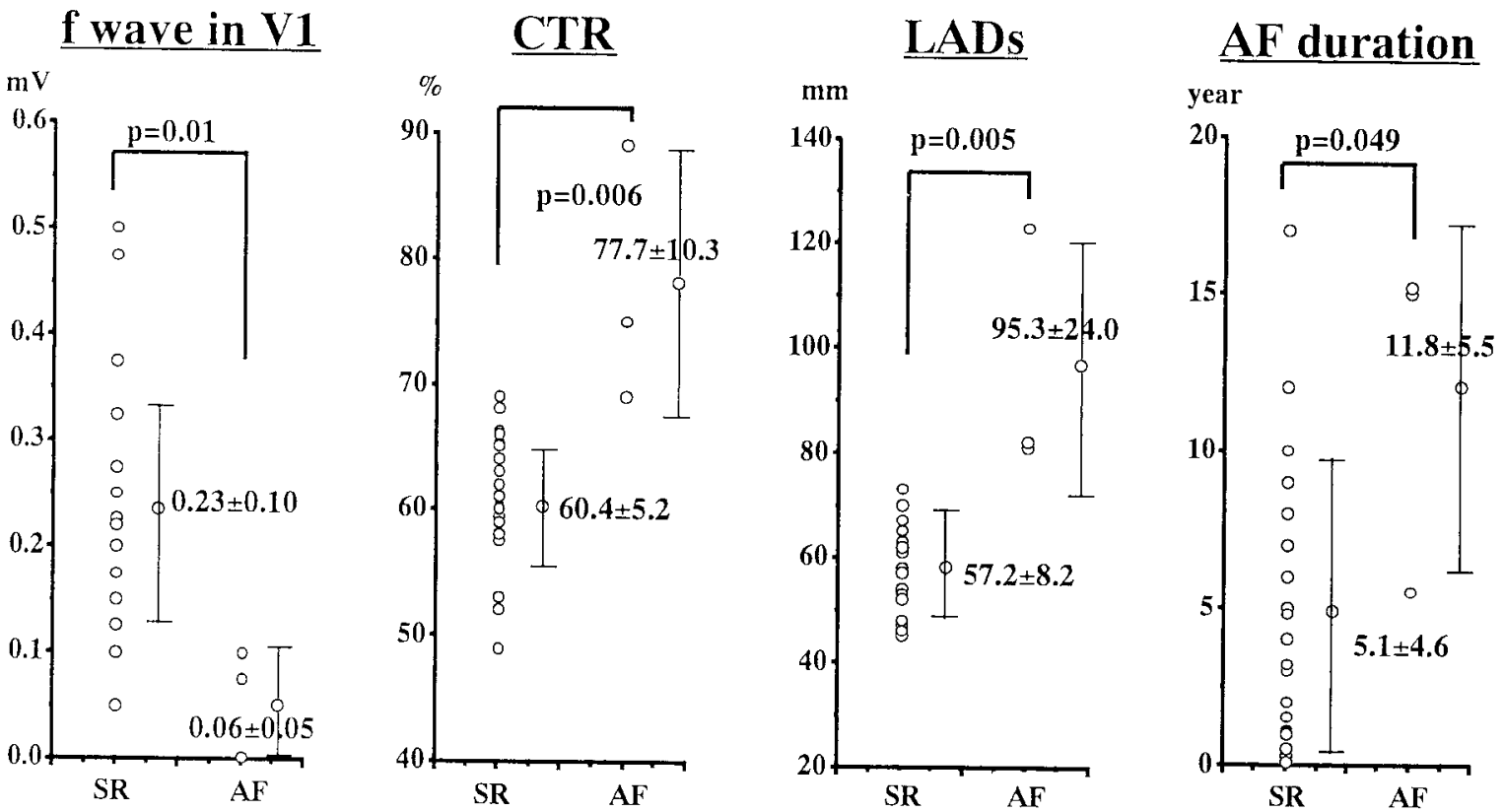

Fig. 2. Preoperative clinical parameters of the SR and AF groups. A low f-wave voltage, a large CTR, a large left atrial systolic dimension ( $L A D s)$, and a long AF duration were predisposing factors for $\mathrm{AF}$ persistence after operation.

minutes (158 \pm 33 minutes), and the cardiopulmonary bypass time was from 159 to 305 minutes (244 \pm 37 minutes).

No patient died. We followed up all of the patients at the outpatient clinic. The follow-up period ranged from 0.8 to 3.4 years $(2.12 \pm 0.85$ years), a total of 63.7 patient-years. One patient in the SR group had a small lacunar infarction at 2.8 months after mitral valve replacement with a mechanical prosthesis.

Postoperative rhythm. Among 30 patients undergoing the complete operation, SR was restored in 27 patients $(90 \%)$, and AF persisted in three patients $(10 \%)$. AF did not recur after the operation in any patient. We evaluated the cardiac rhythm at more than 6 months after the operation. Even in the SR group, two patients showed a tendency toward the development of the sick sinus syndrome with occasional junctional bradycardia, and one other patient had sick sinus syndrome with atrioventricular reentrant tachycardia.

Because an antiarrhythmic drug was necessary to control atrioventricular reentrant tachycardia, it worsened sinus node function, and pacemaker implantation was required. This was the only patient who needed a pacemaker in the group (3.3\%).
Preoperative clinical parameters in relation to postoperative status. There were statistically significant differences of some parameters between the groups, as shown in Fig. 2. A low f-wave voltage, a large CTR, a large left atrium, and a long duration of AF were predisposing factors for the postoperative persistence of AF (Fig. 2).

The f-wave voltage in lead $\mathrm{V}_{1}$ ranged from 0.05 to $0.50 \mathrm{mV}$ (mean $0.23 \pm 0.10 \mathrm{mV}$ ) in the SR group and from 0.01 to $0.1 \mathrm{mV}$ (mean $0.06 \pm 0.05 \mathrm{mV}$ ) in the AF group, showing a statistically significant difference $(p=0.01)$. The CTR ranged from $49 \%$ to $69 \%$ (mean $60.4 \% \pm 5.2 \%$ ) in the SR group and from $69 \%$ to $89 \%$ (mean $77.7 \% \pm 10.3 \%$ ) in the AF group, being significantly smaller in the SR group $(p=0.006)$. The Doppler echocardiographic left atrial systolic dimension ranged from 45 to $73 \mathrm{~mm}$ (mean $57.4 \pm 8.2 \mathrm{~mm}$ ) in the SR group and from 81 to $123 \mathrm{~mm}$ (mean $95.3 \pm 24.0 \mathrm{~mm}$ ) in the AF group, being significantly smaller in the SR group $(p=$ 0.005). The duration of AF was not clear, but we defined it by checking the actual electrocardiographic data in the medical records. It ranged from 0.1 to 17 years (mean $5.1 \pm 4.6$ years) in the SR group and from 5.5 to 15 years (mean $11.8 \pm 5.5$ years) in the AF group, being significantly shorter in 


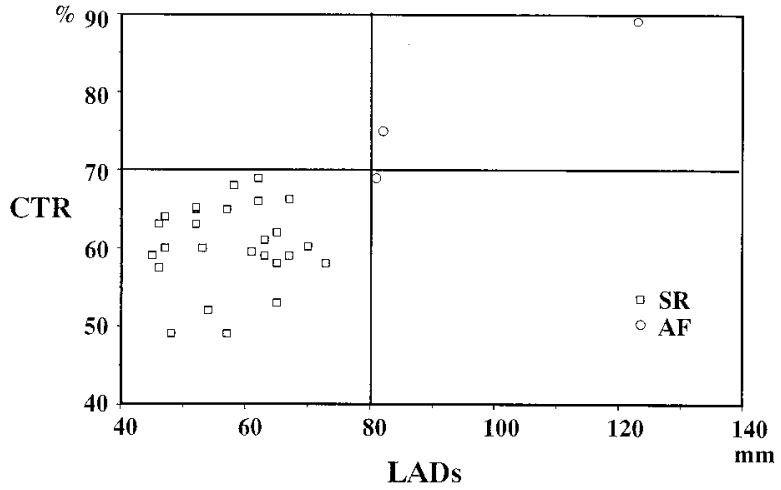

Fig. 3. Correlation between heart size and postoperative rhythm. The SR group was located in the area shown by a CTR less than $70 \%$ and a left atrial systolic dimension (LADs) less than $80 \mathrm{~mm}$.

Table I. $A$ wave in atrioventricular valve flow

\begin{tabular}{ccc}
\hline TMF & TTF & No. of patients \\
\hline+ & + & $18(66.7 \%)$ \\
+ & - & $0(0 \%)$ \\
- & + & $9(33.3 \%)$ \\
- & - & $0(0 \%)$ \\
$18(66.7 \%)$ & $27(100 \%)$ & 27
\end{tabular}

Atrial function after the maze procedure. An A wave was detected in 18 patients $(66.7 \%)$ at transmitral flow $(T M F)$ and in 27 patients $(100 \%)$ at transthoracic flow (TTF) on pulsed Doppler echocardiography.

the SR group $(p=0.049)$. When the relationship between CTR and left atrial systolic dimension was plotted, the SR group was located in the area within a CTR of $70 \%$ and a left atrial systolic dimension of $80 \mathrm{~mm}$ (Fig. 3). No patient resumed SR when the CTR was over $70 \%$ and the left atrial systolic dimension was over $80 \mathrm{~mm}$ before the operation.

To evaluate postoperative atrial function in the SR group, we checked the A waves of transmitral and transtricuspid flow on pulsed Doppler echocardiography. With data obtained more than 6 months after the operation, we evaluated atrial function. An A wave was detected during transmitral flow in 18 patients $(66.7 \%)$ and during transtricuspid flow in 27 patients (100\%; Table I). Atrial function was not normal, as shown in Fig. 4. The ratio of peak velocity at atrial contraction to early diastolic peak velocity (A/E ratio) of transmitral flow was low in patients with the maze procedure as compared with the normal value. ${ }^{9}$

Regarding the restoration of left atrial function, the f-wave voltage, CTR, and left atrial systolic dimension showed no significant difference between the patients with positive and negative A waves, and
Fig. 4. A/E ratio on pulsed Doppler echocardiography after the maze procedure. The $\mathrm{A} / \mathrm{E}$ ratio of transmitral flow was low after the maze procedure as compared with the normal value reported in reference 8. (Reprinted from Am J Cardiol, vol 53, Miyatake K, Okamoto M, Kinoshita N, Owa M, Nakasone I, Sakakibara H, et al, Augmentation of Atrial Contribution to Left Ventricular Inflow With Aging as Assessed by Intracardiac Doppler Flowmetry. p. 586-9, (c) 1984, with permission from Excerpta Medica Inc.)

only the duration of AF showed statistically significant difference $(p=0.011)$ (Fig. 5). Patients who had AF for an extremely long period might not show recovery of left atrial function even after the restoration of SR on the electrocardiogram after the maze operation.

Profile of the patients with AF after operation. As summarized in Fig. 6, the patients with AF after operation had a bigger CTR $(89 \%, 81 \%, 75 \%)$, a larger left atrial cavity $(123,81$, and $82 \mathrm{~mm})$, a lower f-wave voltage, and a longer duration of AF.

\section{Discussion}

It was reported that the original Cox maze procedure has an excellent efficacy, with a $98 \%$ success rate for return to SR from lone $\mathrm{AF}^{3}$ However, it has not been clear whether it was effective or not for chronic AF combined with mitral valve disease. On the other hand, because the modified procedure has become common, a cryolesion is used as a substitute for an actual incision of the atrial wall, and $82 \%$ efficacy has been reported. ${ }^{6}$ In our series, SR was restored in $90 \%$ of the patients, indicating that the maze III procedure itself also has a good efficacy for AF combined with valvular heart disease.

With the maze I procedure, Cox encountered much sinus node dysfunction necessitating the implantation of a pacemaker. Therefore he modified 

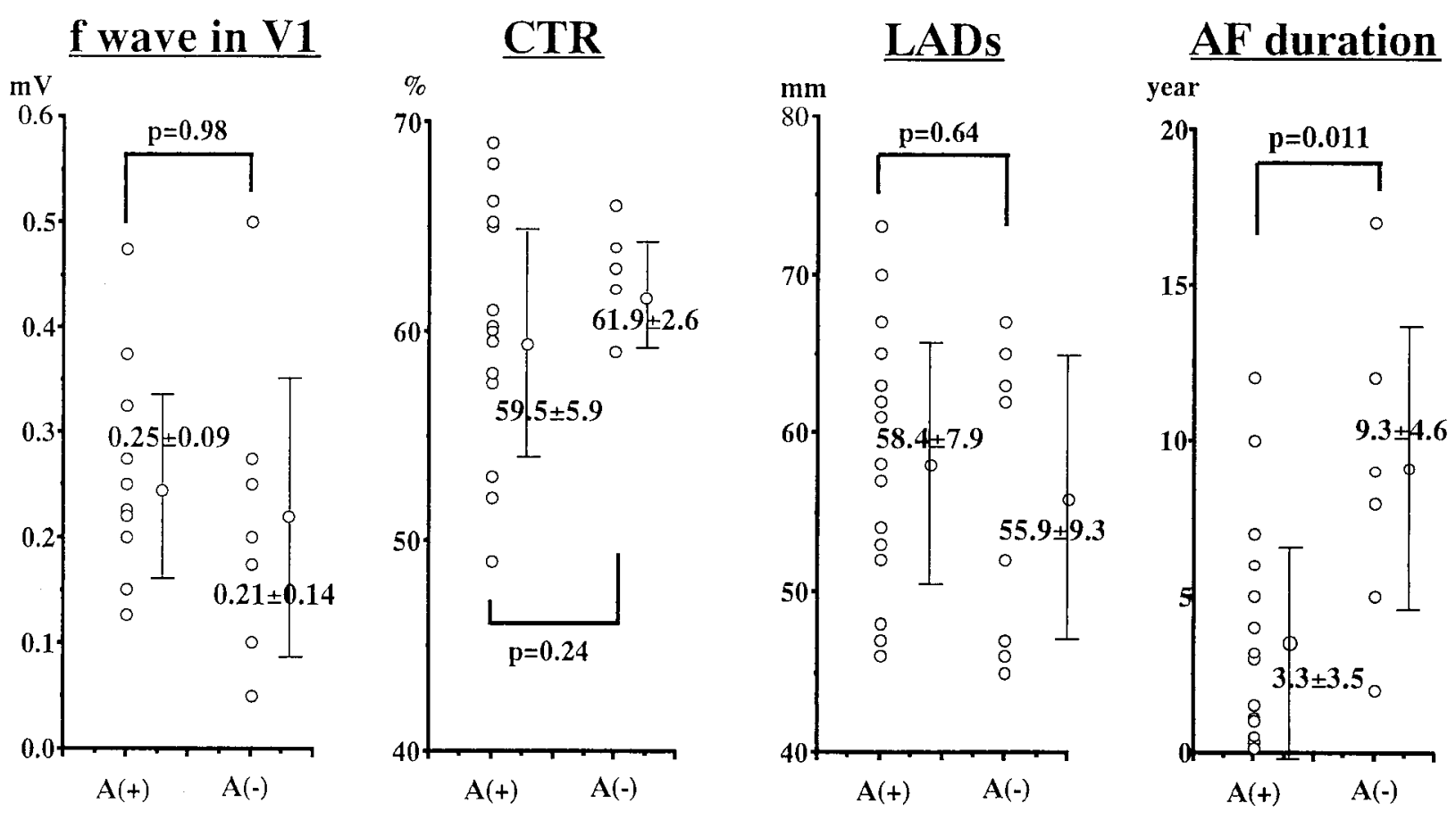

Fig. 5. Restoration of left atrial function after the maze procedure. The f-wave voltage, CTR, and left atrial systolic dimension ( $L A D S$ ) showed no significant differences between the positive and negative A-wave groups. Only the duration of AF showed a statistically significant difference.

his procedure to maze III to prevent postoperative sinus node dysfunction.

There are three patterns of sinus node artery anatomy: the right, left, and posterior types. ${ }^{10}$ The right sinus node artery originates from the proximal right coronary artery, passes across the anteromedial wall of the right atrium, and usually passes in a counterclockwise manner in relation to the superior vena cava and then penetrates the atrial septum below the interatrial bundle. The left sinus node artery arises from the proximal portion of the left coronary artery and courses through the left anterior ramus of the interatrial bundle. The site of the origin of the left posterior sinus node artery varies, but its initial course over the lateral wall of the left atrium between the atrial appendage and the left superior pulmonary vein is very characteristic.

The maze I procedure had the potential to damage all three types of sinus node artery. Cox moved the transverse atriotomy across the dome of the left atrium posteriorly and finally placed the septal incision posterior to the superior vena cava in the maze III procedure. The incision between the isolation incision for the pulmonary veins and the stump of the left atrial appendage was not changed in all types of maze procedure. Therefore injury to the left posterior sinus node artery could not be avoided even with the maze III procedure, and the occurrence of sick sinus syndrome, which necessitated the implantation of a pacemaker after maze III, was reported to be as high as $25 \%{ }^{3}$ We therefore moved this incision to the area between the stump of the left atrial appendage and the posterior mitral anulus and applied a small cryolesion at the anulus like another mitral incision (Fig. 1). Apart from this modification, the procedure was the same as the original maze III involving a "cut and suture" technique. Even though this modification was used, it was still possible for the peripheral portion of the sinus node artery just before entry into the sinus node to be cut when making the incision on the lateral wall of the right atrium. In our series, just one patient needed a pacemaker $(3.3 \%)$ because of bradycardia after medication for atrioventricular reentrant tachycardia. Two other patients had occasional junctional bradycardia, suggesting a tendency for sick sinus syndrome, but it was not severe enough to need a pacemaker. Accordingly, our modification seems to be effective to preserve all types of blood supply to the sinus node, and damage 


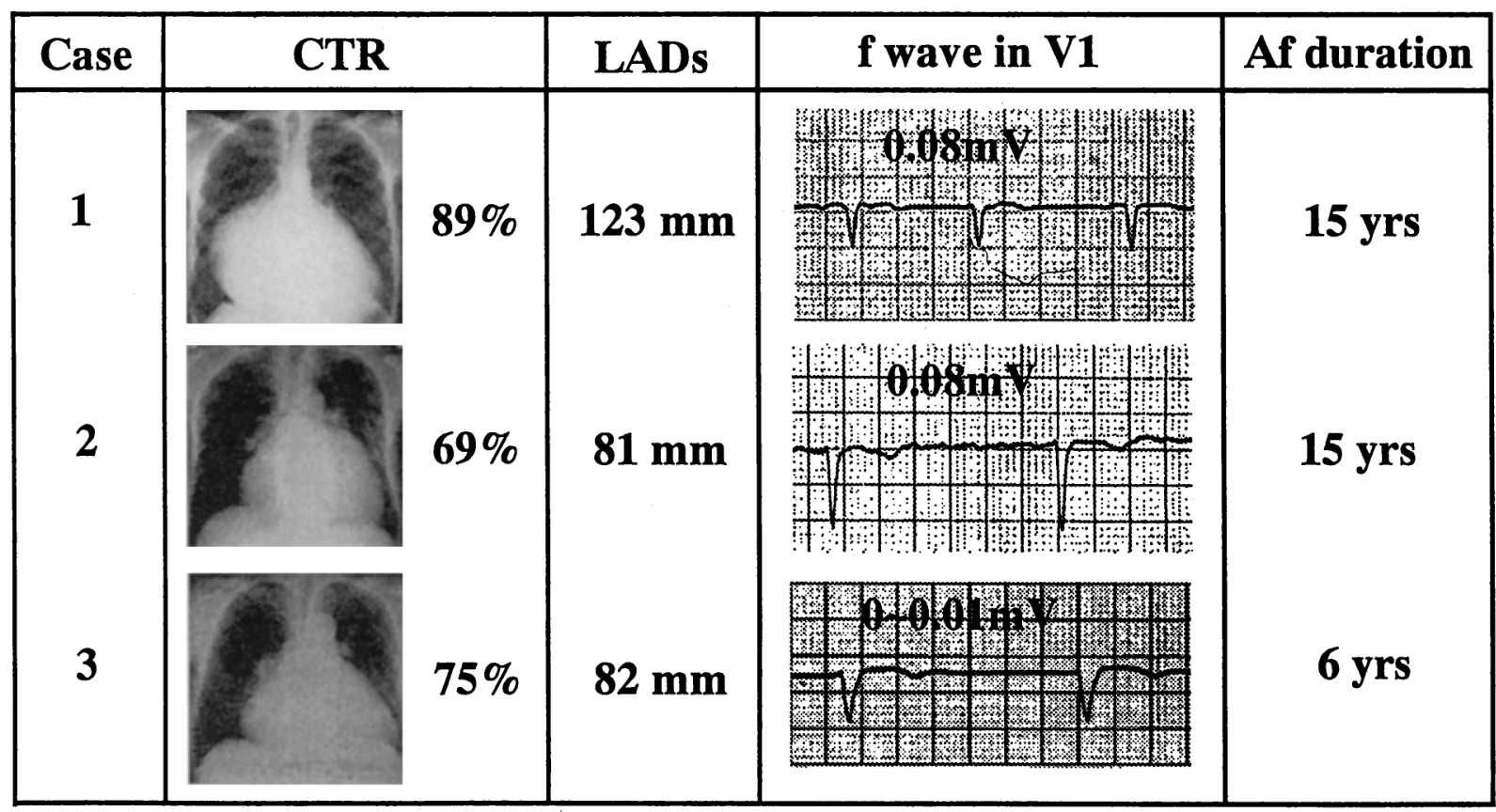

Fig. 6. Profile of the three patients with AF after the maze procedure. They had a bigger CTR, a larger left atrial cavity, a lower f-wave voltage, and a longer AF duration.

to the peripheral portion of the sinus node artery by the incision of the right lateral atrial wall might not impair its function severely.

In this study, we applied a combination of the maze procedure and mitral valve surgery to consecutive patients who had chronic AF with mitral valve disease irrespective of the duration of $\mathrm{AF}$, the severity of symptoms, and the size of the heart.

Chua and associates ${ }^{11}$ reported that mitral valve repair should be done before or soon after the onset of AF to maximize the chance of postoperative SR and all of the patients in their study with a recent onset AF (within 3 months) resumed SR. In our series, the shortest duration of AF was 1.5 months, and this patient recovered SR after operation. However, it was usually difficult to define the exact onset of AF, so we calculated the duration from the earliest date when AF was reliably documented in the medical records. Thus there is a strong possibility that the calculated duration of AF was shorter than the true duration. Therefore if the exact onset of AF was clear and the duration was under 3 months, there might be no indication for the maze procedure in such a patient. On the other hand, the postoperative AF group had a significantly longer duration of $\mathrm{AF}$ before operation, and they showed no recovery of left atrial function even after the restoration of SR.

The patients who did not experience the resumption of SR all had severe dilation of the left atrial cavity, with a CTR of more than $70 \%$ and a left atrial systolic dimension of more than $80 \mathrm{~mm}$. They also had a lower f-wave voltage and a longer duration of AF than the other patients.

Three reoperation cases excluded from present study showed AF after operation after the modified maze procedure with cryolesion as a substitute for real incision because it was thought to be dangerous to use the cut and suture technique because of the severe calcification and adhesions in the area between the left atrial appendage and the mitral anulus.

Among the patients in whom SR was restored after operation, $66.7 \%$ of the left atria and $100 \%$ of the right atria were functioning. The duration of AF was significantly longer in the patients with no left atrial function detected after operation. However, atrial function was still not normal in those with recovery, because the $\mathrm{A} / \mathrm{E}$ ratio was one half to one third of the normal value as in other reports. ${ }^{6,12,13}$ The reason for the low rate of left atrial functional recovery might be severe injury of the left atrial 
myocardium by myocarditis and/or mechanical stress as the result of the mitral valve lesion, because the right atrium showed a contrasting excellent result.

The other important advantage of the maze procedure is the prevention of thromboembolic events. In our series, no patient had an apparent thromboembolic event after the operation, but one patient with SR had a small lacunar infarct with complete recovery at 2.8 months after mitral valve replacement with a mechanical valve. Therefore it seems possible that the maze procedure diminishes the occurrence of thromboembolic events after mitral valve replacement. However, it is too early to decide whether the maze procedure has any efficacy for preventing thromboembolism. We need more patients and a longer follow-up period.

With respect to the need for anticoagulation therapy, mitral valve repair is better than replacement as the type of mitral valve surgery to perform with the maze procedure. A tissue valve is also more suitable than a mechanical valve for replacement. However, a tissue valve is not recommended for younger patients (under the age of 70 years) because of its limited durability in the mitral position. ${ }^{14-16}$ There are arguments that the maze procedure may not be beneficial because anticoagulant therapy is mandatory for patients with a mechanical valve. ${ }^{17}$ Two thirds of our patients had restored left atrial function, and a regular cardiac rhythm might contribute to reducing the risk of thromboembolism even in patients whose atrial function is impaired. Therefore the maze procedure might still benefit patients undergoing mitral valve replacement with a mechanical valve as well as those undergoing valve repair and valve replacement with a tissue valve.

Various methods of modifications of the maze procedure have been developed, including cryolesion as a substitute for actual incision ${ }^{6}$ or a limited procedure at the left atrium (partial maze procedure) ${ }^{5,7}$ Myocardial cryolesions are usually created by a 1 - to 2-minute application of a 6 to $10 \mathrm{~mm}$ cylindrical probe cooled to $-60^{\circ}$ to $-70^{\circ} \mathrm{C}$ with nitrous oxide or carbon dioxide. With a carbon dioxide cryoprobe ( $6 \mathrm{~mm}$ diameter) with a head temperature of $-70^{\circ} \mathrm{C}$ applied for 1 to 2 minutes to a normothermic canine heart during cardiopulmonary bypass, an iceball $19 \pm 1 \mathrm{~mm}$ in diameter was created. ${ }^{18}$ A lower cryoprobe temperature resulted in a larger cryolesion, and the volume of the cryolesions created during profound myocardial hypothermia in the absence of coronary artery perfusion was 6 to 10 times greater than the volume of cryolesions created in normothemic, perfused myocardium. ${ }^{19}$ To achieve interruption of electrical conduction by the creation of cryolesions, profound hypothermia might be necessary, and cryosurgery would usually be done with cardiac arrest induced by the cool cardioplegia. Therefore use of cryolesions as a substitute for actual incision might produce a wide band of frozen atrium that would become noncontractile myocardium and would oppose the purpose of the maze procedure. In the case of limited maze procedures, these methods have no theoretic support from experiments. Therefore we will continue to use "cut and suture" techniques as in the original maze III procedure.

In conclusion, the indications for the maze procedure combined with mitral valve surgery appear to be as follows: the maze III procedure should be done for patients with $\mathrm{AF}$ lasting more than 3 months before operation, a CTR of less than $70 \%$, and a left atrial systolic dimension of less than 80 $\mathrm{mm}$. Patients should be excluded if they have a CTR of $70 \%$ or more and a left atrial systolic dimension of $80 \mathrm{~mm}$ or more, although potential exclusions would be those who have a low f-wave voltage or those in whom the complete procedure cannot be performed because of extensive calcification and severe atrial adhesions.

\section{REFERENCES}

1. Cox JL. The surgical treatment of atrial fibrillation. IV. Surgical technique. J Thorac Cardiovasc Surg 1991;101:584-92.

2. Cox JL. Evolving applications of the maze procedure for atrial fibrillation [Invited Editorial]. Ann Thorac Surg 1993; 55:578-80.

3. Cox JL, Jaquiss RDB, Schuessler RB, Boineau JP. Modification of the maze procedure for atrial flutter and atrial fibrillation. II. Surgical technique of the maze III procedure. J Thorac Cardiovasc Surg 1995;110:485-95.

4. McCarthy PM, Cosgrove DM III, Castle LW, White RD, Klein AL. Combined treatment of mitral regurgitation and atrial fibrillation with valvuloplasty and the maze procedure. Am J Cardiol 1993;71:483-6.

5. Brodman RF, Frame R, Fisher JD, Kim SG, Roth JA, Ferrick KJ. Combined treatment of mitral stenosis and atrial fibrillation with valvuloplasty and a left atrial maze procedure. J Thorac Cardiovasc Surg 1994;107:622-4.

6. Kosakai Y, Kawaguchi AT, Isobe F, Sasako Y, Kilo Y, Kawashima Y. Cox maze procedure for chronic atrial fibrillation associated with mitral valve disease. J Thorac Cardiovasc Surg 1994;108:1049-55.

7. Sueda T, Nagata H, Shikata H, Orihashi K, Morita S, Sueshiro M, et al. Simple left atrial procedure for chronic atrial fibrillation associated with mitral valve disease. Ann Thorac Surg 1996;62:1796-800.

8. Isobe F. The surgical treatment for atrial fibrillation. In: Postgraduate education committee of the Japanese association for 
thoracic surgery. Advances of thoracic surgery. Tokyo: Japanese Association for Thoracic Surgery, 1995. p. 203-16.

9. Miyatake K, Okamoto M, Kinoshita N, Owa M, Nakasone I, Sakakibara H, et al. Augmentation of atrial contribution to left ventricular inflow with aging as assessed by intracardiac Doppler flowmetry. Am J Cardiol 1984;53:586-9.

10. McAlpine WA. The arteries to the atria and to the A.V. node. In: McAlpine WA, editor. Heart and coronary arteries: an anatomical atlas for clinical diagnosis, radiological investigation, and surgical treatment. New York: Springer-Verlag; 1975. p. 151-62.

11. Chua YL, Schaff HV, Orszulak TA, Morris JJ. Outcome of mitral valve repair in patients with preoperative atrial fibrillation. J Thorac Cardiovasc Surg 1994;107:408-15.

12. Itoh $\mathrm{T}$, Okamoto $\mathrm{H}$, Nimi $\mathrm{T}$, Morita $\mathrm{S}$, Sawazaki M, Ogawa $\mathrm{Y}$, et al. Left atrial function after Cox's maze operation concomitant with mitral valve operation. Ann Thorac Surg 1995;60:354-9.

13. Feinberg MS, Waggoner AD, Kater KM, Cox JL, Perez JE. Echocardiographic automatic boundary detection to measure left atrial function after the maze procedure. J Am Soc Echocardiogr 1995;9:139-48.
14. Jamieson WR, Munro AI, Miyagishima RT, Allen P, Burr LH, Tyers GF. Carpentier-Edwards standard porcine bioprosthesis: clinical performance to seventeen years. Ann Thorac Surg 1995;60:999-1006.

15. Fann JI, Miller DC, Moore KA, Mitchell RS, Oyer PE, Stinson EB, et al. Twenty-year clinical experience with porcine bioprostheses. Ann Thorac Surg 1996;62:1301-11.

16. Aupart M, Babuty D, Neville P, Faucher L, Sirinelli A, Marchard M. Influence of age on valve related events with Carpentier-Edwards pericardial bioprosthesis. Eur J Cardiothorac Surg 1997;11:929-34.

17. Kobayashi J, Kosakai Y, Isobe F, Sasako Y, Nakano K, Eishi $\mathrm{K}$, et al. Rationale of the Cox maze procedure for atrial fibrillation during redo mitral valve operations. J Thorac Cardiovasc Surg 1996;112:1216-22.

18. Hunt GB, Chard RB, Johnson DC, Ross DL. Comparison of early and late dimensions and arrhythmogenicity of cryolesions in the normothermic canine heart. J Thorac Cardiovasc Surg 1989;97:313-8.

19. Holman WL, Ikeshita M, Douglas JM, Smith PK, Cox JL. Cardiac cryosurgery: effects of myocardial temperature on cryolesion size. Surgery 1983;93:268-72.

\section{Bound volumes available to subscribers}

Bound volumes of The Journal of Thoracic and Cardiovascular Surgery are available to subscribers (only) for the 1998 issues from the Publisher, at a cost of $\$ 122.00$ for domestic, \$151.94 for Canadian, and \$142.00 for international subscribers for Vol. 115 (January-June) and Vol. 116 (July-December). Shipping charges are included. Each bound volume contains a subject and author index and all advertising is removed. Copies are shipped within 60 days after publication of the last issue of the volume. The binding is durable buckram with the Journal name, volume number, and year stamped in gold on the spine. Payment must accompany all orders. Contact Mosby, Inc., Subscription Services, 11830 Westline Industrial Drive, St. Louis, Missouri 63146-3318, USA; phone 800-453-4351 or 314-453-4351.

Subscriptions must be in force to qualify. Bound volumes are not available in place of a regular Journal subscription. 